\title{
ESTIMASI KARBON VEGETASI MANGROVE DI KELURAHAN PINTU KOTA KECAMATAN LEMBEH UTARA KOTA BITUNG
}

\author{
(Mangrove Carbon Vegetation Estimation In Kelurahan Pintu Kota Sub district \\ Lembeh Utara Kota Bitung)
}

\author{
Gerardus M. Tiolong $^{1 *}$, Antonius P. Rumengan ${ }^{1}$, Calvyn F.A. Sondak ${ }^{1}$, Farnis B. \\ Boneka $^{1}$, N. Gustaf F. Mamangkey ${ }^{1}$, Cristine Kondoy ${ }^{2}$
}

1. Program Studi IImu Kelautan, FPIK, Unsrat.

2. Program Studi Manajemen Sumberdaya Perairan, FPIK, Unsrat.

*e-mail : Maykeltiolong94@gmail.com

\begin{abstract}
Global warming is one of the issues in the world today, marked by an increase in the temperature of the earth which is directly related to greenhouse gases. Mangrove forest is one of the potential parameters to be studied from the Blue Carbon ecosystem. Estimates of carbon storage in mangrove forests are so large that it is important to calculate carbon stock estimates in mangrove vegetation. This study aims to estimate the carbon content of mangrove trees in the Pintu Kota Village, North Lembeh District, Bitung City. The method used in this research activity is the Line Transect method. Biomass calculation of mangrove trees, using allometric equations. Based on the results of the study after identified mangroves in Pintu Kota Village there were 4 types of mangroves, which consisted of, Rhizophora apiculata, Rhizophora mucronata, Bruguiera gymnorhiza and Soneratia alba. The highest total value of the highest biomass was found at station (2) with a value of 124.01 tons / ha, then at station (3) at 99.02 tons / ha. While the lowest biomass results are at station (1) of 84.15 tons / ha. sehinggah the estimation results of the highest potential carbon content is at the station (2) with a value of 58.29 tons $C$ / ha then at station (3) of 46.54 tons $C$ / ha, while the estimated yield of the lowest carbon content is also found at the station (1) with a value of 39.55 tons $\mathrm{C} / \mathrm{ha}$.
\end{abstract}

Keywords: Carbon, mangrove, Pintu Kota Village, Bitung City

Pemanasan global merupakan salah satu isu di dunia saat ini, ditandai dengan adanya peristiwa meningkatnya suhu bumi yang terkait langsung dengan gas-gas rumah kaca. Hutan mangrove merupakan salah satu potensi yang menjadi parameter untuk dikaji dari ekosistem Blue Carbon. Perkiraan penyimpanan karbon pada hutan mangrove begitu besar sehingga penting untuk menghitung estimasi simpanan karbon pada vegetasi mangrove. Penelitian ini bertujuan untuk Mengestimasi kandungan karbon pohon mangrove yang ada di Kelurahan Pintu Kota Kecamatan Lembeh Utara Kota Bitung. Metode yang digunakan dalam kegiatan penelitian ini ialah metode transek garis (Line Transect). Penghitungan biomassa pohon mangrove, menggunakan persamaan allometrik. Berdasarkan dari hasil penelitian setelah diindentifikasi mangrove di Kelurahan Pintu Kota terdapat 4 jenis mangrove, yang terdiri dari, Rhizophora apiculata, Rhizophora mucronata, Bruguiera gymnorhiza dan Soneratia alba. Diperoleh hasil total nilai rata-rata biomassa yang tertinggi terdapat pada stasiun (2) dengan nilai 124,01 ton/ha, kemudian pada stasiun (3) sebesar 99,02 ton/ha. Sedangkan hasil biomassa terendah terdapat pada stasiun (1) sebesar 84,15 ton/ha. sehinggah hasil estimasi potensi kandungan karbon yang tertinggi terdapat pada stasiun (2) dengan nilai 58,29 ton $\mathrm{C} / \mathrm{ha}$ kemudian pada stasiun (3) sebesar 46,54 ton C/ha, sedangkan hasil estimasi potensi kandungan karbon terendah juga terdapat pada stasiun (1) dengan nilai 39,55 ton C/ha.

Kata kunci: Karbon, mangrove, Kelurahan Pintu Kota, Kota Bitung. 


\section{PENDAHULUAN}

Hutan mangrove merupakan salah satu ekosistem wilayah pesisir dan lautan yang sangat penting bagi kehidupan manusia dan keberlangsungan makhluk hidup yang tinggal di dalamnya atau di sekitarnya. Zainuddin dan Gunawan (2014) menyatakan luas hutan mangrove di Indonesia mencapai $25 \%$ dari total luas hutan mangrove di dunia. Luas hutan mangrove Indonesia antara 2,5 hingga 4,5 juta hektar.

Menurut Sasawu dkk., (2016) mangrove merupakan jenis tumbuhan tropis dan subtropis yang mampu bertahan hidup pada kadar salinitas air yang relative tinggi dan substrat berlumpur. Mangrove merupakan sumber daya alam daerah pesisir yang mempunyai manfaat sangat luas baik secara ekologis, ekonomis, maupun sosial (Paruntu $d k k, 2017)$. Selain itu, Mangrove dan tumbuhan air menyerap karbon dioksida dan mengubahnya menjadi karbon organik yang disimpan dalam biomassa tubuhnya seperti, akar, batang, daun dan bagian lainnya (Hairiah dan Rahayu, 2007; Tidore dkk.,2018; Tilaar dkk., 2019).

Mangrove di Kelurahan Pintu Kota merupakan mangrove yang terletak sangat dekat dengan Pelabuahan Samudra Bitung. Mangrove di lokasi penelitian ini telah dilindungi oleh pemerintah Kota Bitung dan bahkan telah dijadikan tempat wisata mangrove. Belum ada laporan tentang simpanan karbon yang ada di Kelurahan Pintu Kota. Tujuan dari penelitian ini agar dapat mengestimasi karbon vegetasi mangrove sebagai peningkatan nilai ekologi mangrove di Kelurahan Pintu Kota Bitung.

\section{METODE PENELITIAN}

\section{Waktu dan Tempat Penelitian}

Pelaksanaan penelitian ini dilakukan selama 3 bulan (Maret 2019 Mei 2019). Penelitian dilakukan di Kelurahan Pintu Kota, Kecamatan Lembeh Utara Kota Bitung. Metode yang digunakan dalam kegiatan penelitian ini ialah metode Transek garis (Line Transect) untuk mengetahui vegetasi mangrove yang ada di Kelurahan Pintu Kota. Data yang diambil ialah data biomassa mangrove bagian atas (above ground biomass).

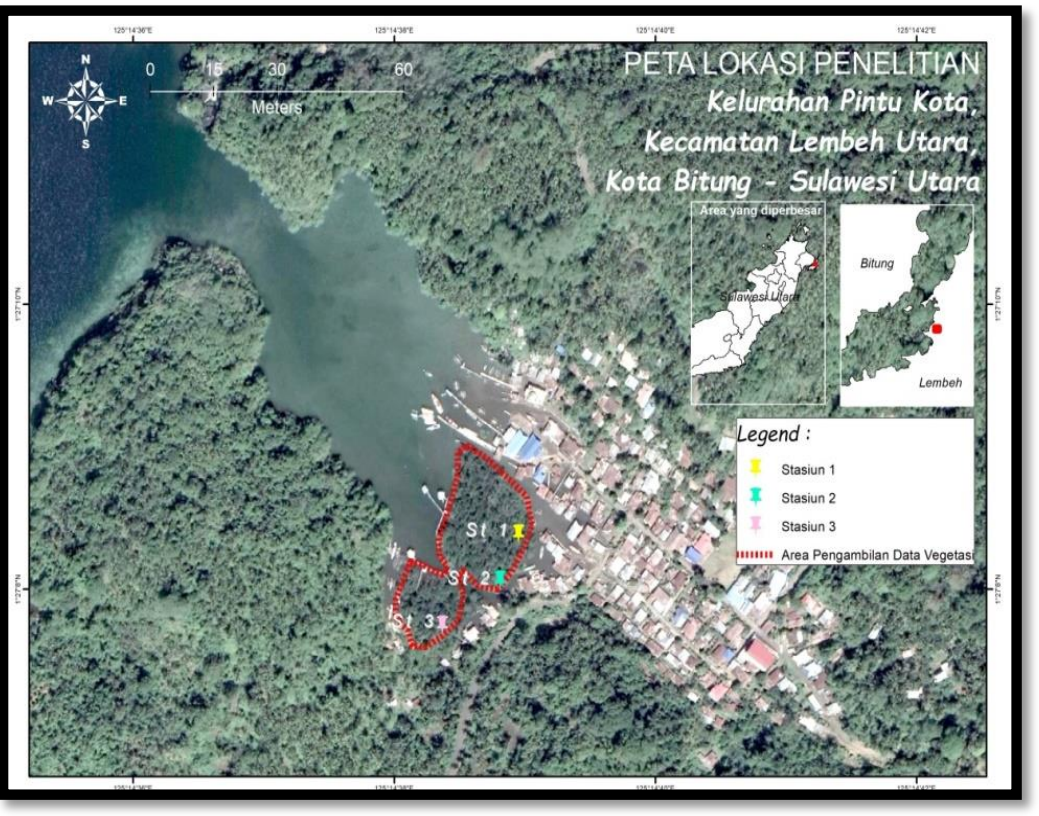

Gambar 1. Peta Pengambilan Sampel

\section{Pengambilan Data}

Untuk pengambilan data vegetasi pohon dilakukan sebayak 3 transek garis
(Line Transect) pada bagian stasiun 1, stasiun 2 dan stasiun 3 ekositem mangrove di Kelurahan Pintu Kota. 
Masing-masing transek sepanjang ketebalan mangrove dari arah darat ke laut tegak lurus garis pantai. Di setiap jalur transek dengan jarak sepanjang $15 \mathrm{~m}$ sehingga jarak dari kuadran 1 sampai pada kuadran 2 adalah $25 \mathrm{~m}$, dengan terdapat kuadran dengan ukuran $10 \times 10$ m2 yang terbuat dari tali plastik, bentuk

\section{Alat dan Bahan}

Peralatan yang digunakan pada penelitian ini, antara lain meteran roll, tali plastic, GPS (Global Positioning System), data sheet, kamera handphone dan meteran jahit.

\section{Identifikasi Nama Jenis Pohon}

Data-data mengenai jenis pohon mangrove yang ada pada setiap kuadran kemudian dicatat jenis-jeninya, pada identifikasi jenis mangrove yakni kuadran $10 \times 10 \mathrm{~m}^{2}$ yang masuk dalam kategori pohon. Identifikasi jenis mangrove dengan menggunakan buku indentifikasi (Noor et al., 2006).. kuadran yang digunakan adalah persegi. Jenis mangrove yang masuk dalam kuadran dicatat jumlah, jenis dan di ukur diameter batang setinggi dada $\mathrm{DBH}$-nya (Diameter at breast height) dalam data sheet.

\section{Pengambilan Data Biomassa Pohon}

Pengukuran $\mathrm{DBH}$ (diameter at breast height). Diameter pohon yang diukur pada ketinggian $1.3 \mathrm{~m}$ di atas permukaan tanah atau sesuai kaidah pengukuran yang ditentukan. Pengukuran dilakukan pada pohon berdiameter $\geq 10$ $\mathrm{cm}$ menggunakan pita meter. Data yang diperoleh yaitu keliling/lingkar pohon (SNI 7724:2011).

\section{Perhitungan Karbon Dari Biomassa}

Menghitung total cadangan karbon hutan didasarkan pada kandungan biomassa. Untuk menghitung biomassa pohon mangrove digunakan persamaan allometrik umum sebagai berikut :

Tabel 1. Persamaan allometrik beberapa jenis mangrove.

\begin{tabular}{llc}
\hline \multicolumn{1}{c}{ Jenis Mangrove } & \multicolumn{1}{c}{ Persamaan allometric } & Sumber \\
\hline Rhizophora mucronata & $\mathrm{B}=0.128(\mathrm{D})^{2.60}$ & (Fromard et al., 1998) \\
Rhizophora apiculata & $\mathrm{B}=0.043 \mathrm{D} 2.63$ & (Amira, 2008) \\
Bruguiera gymnorhiza & $\mathrm{B}=0.0754(\mathrm{D})^{2.505^{*}} \rho$ & (Kauffman \& Donato, 2012) \\
Sonneratia alba & $\mathrm{B}=0.3841(\mathrm{D}) 2.101^{\star} \rho$ & (Kauffman \& Donato, 2012) \\
\hline
\end{tabular}

Berat Jenis :

Bruguiera gymnorhiza $=0.699$

Sonneratia alba $=0.475$

Keterangan :

$$
\begin{aligned}
& B=\text { Biomassa }\left(\mathrm{kg} / \mathrm{m}^{2}, \text { ton } / \mathrm{ha}\right) \\
& D=\text { Diameter }(\mathrm{cm}) \\
& \rho=\text { Berat jenis tumbuhan }\left(\mathrm{g} / \mathrm{cm}^{3}\right)
\end{aligned}
$$

\section{Menghitung Total Cadangan Karbon}

Penghitungan karbon dari biomassa menggunakan rumus SNI no. 7724 tahun $2011 \quad$ sebagai $\quad$ berikut
$C b=B x \%$ organi

Penghitungan cadangan karbon per hektar untuk biomassa di atas permukaan tana dapat menggunakan persamaan sebagai berikut :

$$
C_{n}=\frac{C_{x}}{1000} \times \frac{10000}{l_{\text {plot }}}
$$




\section{HASIL DAN PEMBAHASAN}

\section{Biomassa Mangrove Di Kelurahan Pintu Kota Kecamatan Lembeh Utara Kota Bitung}

Kelurahan Pintu Kota adalah, salah satu Kelurahan di Kecamatan Lembeh Utara, Kota Bitung, Sulawesi Utara, Indonesia. Kelurahan Pintu memiliki kawasan hutan mangrove dengan luasan 1,3 hektar. Setelah diindentifikasi mangrove di Kelurahan Pintu Kota terdapat 4 jenis mangrove, yang terdiri dari, Rhizophora apiculata, Rhizophora mucronata, Bruguiera gymnorhiza dan Soneratia alba. Data biomassa mangrove di Kelurahan Pintu Kota Kecamatan Lembeh utara Kota Bitung yang diperoleh selama penelitian pada Gambar 2.

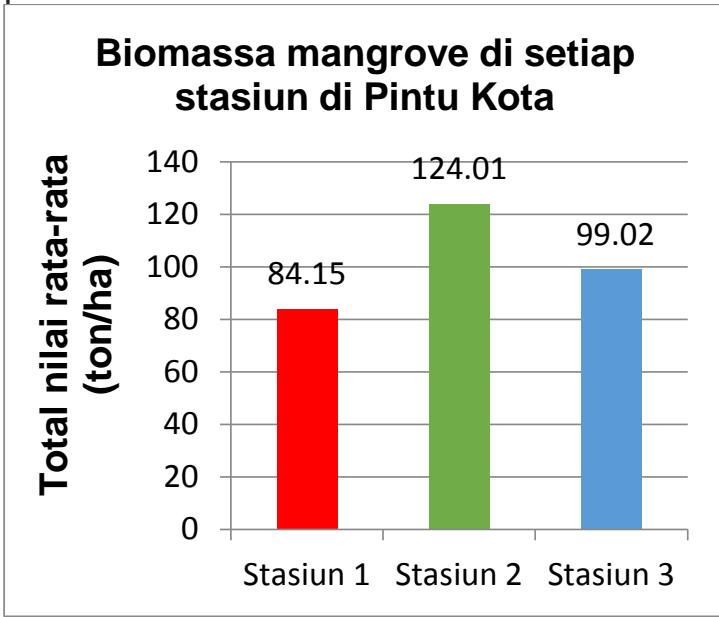

Gambar 2. Perbandingan total nilai Rata-rata Kandungan biomassa setiap stasiun.

Berdasarkan gambar 2 di atas nilai rata-rata biomassa mangrove di Kelurahan Pintu Kota paling tinggi terdapat di Stasiun 2 sebanyak 124,01 ton/ha, sedangkan pada stasiun 3 sebanyak 99,02 ton/ha,rata-rata biomassa mangrove paling sedikit terdapat di Stasiun 1 sebanyak 84,15 ton/ha. Sugirahayu dan Rusdiana (2011) menyatakan bahwa perbedaan biomassa di masing-masing penutupan lahan di pengaruhi oleh jumlah dan kerapatan pohon, jenis pohon, faktor lingkungan yang meliputi penyinaran matahari, kadar air, suhu dan kesuburan tanah yang mempengaruhi laju fotosintesis. Menurut IPCC (2006) konsentrasi karbon yang terkandung dalam bahan organik yaitu sebesar $47 \%$. Untuk mengestimasi jumlah karbon tersimpan yaitu dengan mengalikan 0,47 dengan nilai biomassa.

Simpanan Karbon Mangrove Di Kelurahan Pintu Kota Kecamatan Lembeh Utara Kota Bitung

Menurut Murdiyarso (1999), potensi penyerapan gas karbondioksida $\left(\mathrm{CO}_{2}\right)$ diperoleh melalui perhitungan, perkalian kandungan karbon terhadap besarnya serapan karbondioksida $\left(\mathrm{CO}_{2}\right)$. Data biomassa mangrove di Kelurahan Pintu Kota Kecamatan Lembeh utara Kota Bitung yang diperoleh selama penelitian pada Gambar 3.

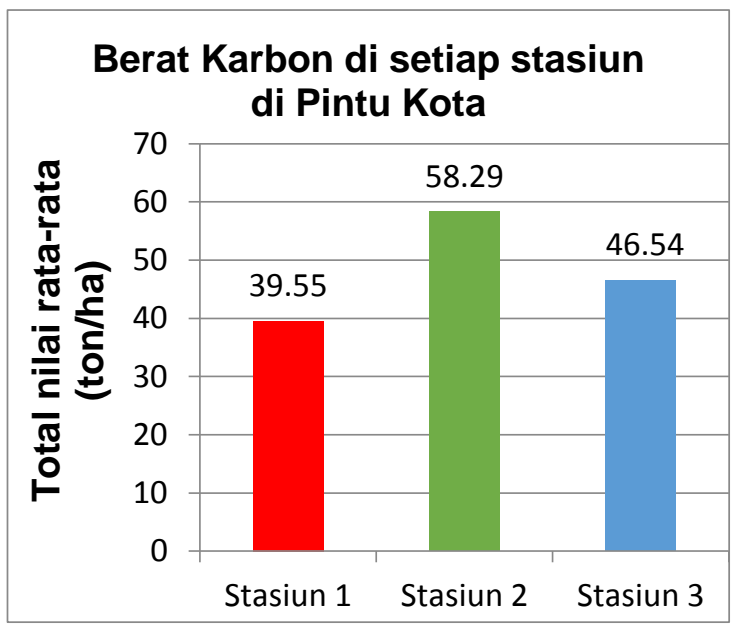

Gambar 3. Perbandingan total nilai ratarata kandungan karbon setiap stasiun.

Hasil estimasi kandungan karbon pohon mangrovepada Gambar 3 terlihat total nilai rata-rata karbon biomassa mangrove paling tinggi terdapat di Stasiun 2 sebanyak 58,29 ton/ha di karenakan di stasiun 2 jumlah pohon lebih bnyak, dengan ukuran batang lebih besar dan stasiun ini berada pada bagian tengah ekosistem mangrove di bandingkan dengan stasiun lain. Sedangkan pada stasiun 3 sebayak 46,54 ton/ha, pada stasiun ini tidak terlalu besar kandungan karbonnya karena pada stasiun ini bersampingan dengan pemukiman warga yang menyebabkan adanya aktivitas manusia yang menyebabkan ketebalan mangrove pada stasiun ini berkurang. Kandungan karbon biomassa mangrove 
paling sedikit terdapat di stasiun 1 sebanyak 39,55 ton/ha. Di stasiun 1 ini lebih sedikit karena jumlah pohon tidak terlalu banyak dengan ukuran batang lebih kecil di bandingkan dengan stasiun 2 dan 3. Pada stasiun 1 ini juga terdapat genangan limbah buangan minyak yang mengakibatkan sebagian pohon mangrove mati. Adapun akibat dari aktifitas kapal sehari-hari pada Pelabuhan Samudra Bitung. Hasil penelitian menunjukan bahwa nilai simpanan karbon pada mangrove yang ada di Kelurahan Pintu Kota adalah sebesar 48,12 ton C/ha. Di bandingkan dengan simpanan karbon yang diperoleh di Teluk Totok, Sulawesi Utara, lebih besar yang mendapatkan simpanan karbon sebesar 63,7 ton $\mathrm{C} /$ ha (Rumengan et al.,2018).

Chanan (2012) menyatakan bahwa setiap penambahan kandungan biomassa akan diikuti oleh penambahan kandungan karbon, hal ini menjelaskan bahwa karbon dan biomassa memiliki korelasi yang positif sehingga apapun yang menyebabkan peningkatan ataupun penurunan biomassa maka akan menyebabkan peningkatan atau penurunan kandungan karbon. Fathoni (2010) menyatakan bahwa cadangan karbon pada berbagai jenis dan umur tanaman berbeda-beda maka cadangan karbon dan kandungan biomassa cenderung semakin besar dengan meningkatnya umur tanaman.

\section{KESIMPULAN DAN SARAN Kesimpulan}

Dari hasil penelitian yang dilakukan di Kelurahan Pintu Kota Kecamatan Lembeh Utara Kota Bitung, setelah diindentifikasi mangrove di Kelurahan Pintu Kota terdapat 4 jenis mangrove, yang terdiri dari, Rhizophora apiculata, Rhizophora mucronata, Bruguiera gymnorhiza dan Soneratia alba. Dari hasil penelitian diperoleh hasil total biomassa rata-rata 102,39 Ton/ha. sedangkan nilai kandungan karbon dengan nilai rata-rata 48,12 ton $\mathrm{C} / \mathrm{ha}$.

\section{Saran}

Pengelolaan hutan mangrove perlu disosialisasikan kepada beberapa instansi terkait dan masyarakat sekitar hutan mangrove di Kelurahan Pintu Kota, disertai kegiatan pengawasan dan pengendalian langsung di lapangan dan Identifikasi jenis serta pengukuran biomassa dan kandungan karbon pada ekosistem mangrove sebaiknya dilakukan secara berkelanjutan secara time series.

\section{DAFTAR PUSTAKA}

Amira. 2008. Pendugaan Biomassa Jenis Rhizophora apiculataBl di Hutan Mangrove Batu Ampar, Kabupaten Kubu Raya, Kalimantan Barat.Fakultas Kehutanan Institut Pertanian Bogor.

Chanan, M. 2012. Pendugaan Cadangan Karbon (C) Tersimpan di Atas Permukaan Tanah pada Vegetasi Hutan Tanaman Jati (Tectona Grandis Linn. F) (Di RPH Sengguruh BKPH Sengguruh KPH Malang Perum Perhutani II Jawa Timur). Jurnal Gamma. 7(2): 6173.

Fathoni, T. 2010. Cadangan Karbon Pada Berbagai Tipe Hutan dan Jenis Tanaman Di Indonesia. Pusat Penelitian dan Pengembangan Perubahan Iklim dan Kebijakan. Kampus Balitbang Kehutanan. Bogor.

Fromard F, Puig H, Mougin E, Betoulle JL, Cadamuro L.1998. Structure, above-ground biomass and dynamics of mangrove ecosystems: new data from French Guiana. Oecologia 115:39-53.

Hairiah, K., dan Rahayu, S., 2007. Petunjuk Praktis Pengukuran Karbon Tersimpan Di Bagian Macam Penggunaan Lahan. World Agroforestry Centre ICRAF Southeast Asia. Bogor.

IPCC (Intergovermental Panel On Climate Change), 2006. Guidelines For National Greenhouse Gas 
Inventories, Agriculture, Forestry And Other Land Use. Keith Paustian, N. H. Ravindranath, Andre Van Amstel, Michael Gytarsky, Werner A. Kurz, Stephen Ogle, Gary Richards, And Zoltan Somogyi: The Institute For Global Enviromental Strategies (IGES) 9 Hal.

Kepel, T.L. Devi D.S, Restu N.A.A, Hadiwijaya L.S dan Andreas A.H. 2017. Nilai Penting dan Estimasi Nilai Ekonomi Simpanan Karbon Vegetasi Mangrove Di Kema, Sulawesi Utara. Jurnal Kelautan Nasional, Vol. 12, No 1, April 2017, Hal. 19-26.

Kauffman, J.B. dan D.C. Donato., 2012. Protocols for The Measurement, Monitoring and Reporting of Structure, Biomass and Carbon Stocks in Mangrove Forest. CIFOR. Bogor - Indonesia. 40 pp.

Murdiyarso D. 1999. Perlindungan Atmosfer Melalui Perdagangan Karbon: Paradigma Baru Dalam Sektor Kebutuhan. Orasi IImiah Guru Besar Tetap IImu Atmosfer. Fakultas MIPA IPB. Bogor. $47 \mathrm{Hal}$.

Noor, R., Khazali, Y.M., dan Suryadiputra, I.I.N., 2006. Panduan Pengenalan Mangrove di Indonesia. PHKA/WIIP. Bogor.

Paruntu C P., A. B. Windarto, A. P. Rumengan. 2017. Karakteristik Komunitas Mangrove Desa Motandoi Kecamatan Pinolosian Timur Kabupaten Bolaang Mongondow Selatan Provinsi Sulawesi Utara. Jurnal Pesisir dan Laut Tropis. Vol.1 No.2. Hal. 5365.

Restu, N.A., Agustin, R., Terry, L., Nasir, S., Mariska, A., August, D., Devi, D.S., Yusmina, P., Peter, M., Andreas, H. 2013. Karbon Stok dan Struktur Komunitas Mangrove Sebagai Blue Carbon di Tanjung Lesung, Banten. Pusat Penelitian dan Pengembangan Sumberdaya Pesisir dan Laut.
Rumengan A. P., Mantiri D. M. H., Rompas R., Hutahaean A., Kepel T. L., Paruntu C. P., Kepel R. C., Gerung G. S., 2018 Carbon stock assessment of mangrove ecosystem in Totok Bay, southeast Minahasa Regency, North Sulawesi, Indonesia. AACL Bioflux 11(4):1280-1288.

Sasawu, J., Kusen, J.D., Schaduw, J.N.W. 2016. Struktur komunitas mangrove di kelurahan tongkaina manado. Jurnal pesisir dan laut tropis. FPIK Universitas Sam Ratulangi. Vol. 2 (1).

SNI. 2011. Pengukuran Dan Penghitungan Cadangan Karbon Pengukuran Lapangan Untuk Penaksiran Cadangan Karbon Hutan (Ground Based Forest Carbon Accounting), SNI 7724.

Sugirahayu, L., dan Rusdiana, O. 2011. Perbandingan Simpanan Karbon pada Beberapa Penutupan Lahan di Kabupaten Paser, Kalimantan Timur Berdasarkan Sifat Fisik dan Sifat Kimia Tanahnya. Jurnal Silvikultur Tropika. Vol. 02 No. 03. Hal 149-155.

Tidore, F. Rumengan, A. Sondak, C.F.A, Mangindaan, R.E.P. Runtuwene, H.C.C. Pratasik, S.B. 2018. Estimasi Kandungan Karbon (C) pada Serasah Daun Mangrove di Desa Lansa, Kecamatan Wori, Kabupaten Minahasa Utara. Jurnal Pesisir dan Laut Tropis, Vol 2, No. 1, Hal 53-58.

Tilaar F. F., Katuuk V., Salaki M. S., Sondakh S. J., Mantiri D. M. H., Kepel R. C., Lasabuda R., Mantiri R. O. S. E., Boneka F. B., Gerung G. S., Wagey B. T., Gaol J. L., Potential carbon stocks of seagrass species in Bunaken Island, North Sulawesi, Indonesia. AES Bioflux 11(2):59-66. 